Tjalling C. Koopmans Research Institute Tplligh Aoopman

Discussion Paper Series nr: 12-17

\title{
Deep determinants or interactions: explaining spatial patterns in human rights
}

Gerrit Faber

M ichiel Gerritse 


\section{Tjalling C. Koopmans Research Institute Utrecht School of Economics \\ Utrecht University}

Kriekenpitplein 21-22

3584 EC Utrecht

The Netherlands

telephone $\quad+31302539800$

fax +31302537373

website www.koopmansinstitute.uu.nl

The Tjalling C. Koopmans Institute is the research institute and research school of Utrecht School of Economics.

It was founded in 2003, and named after Professor Tjalling C. Koopmans, Dutch-born Nobel Prize laureate in economics of 1975.

In the discussion papers series the Koopmans Institute publishes results of ongoing research for early dissemination of research results, and to enhance discussion with colleagues.

Please send any comments and suggestions on the Koopmans institute, or this series to J.M.vanDort@uu.nl

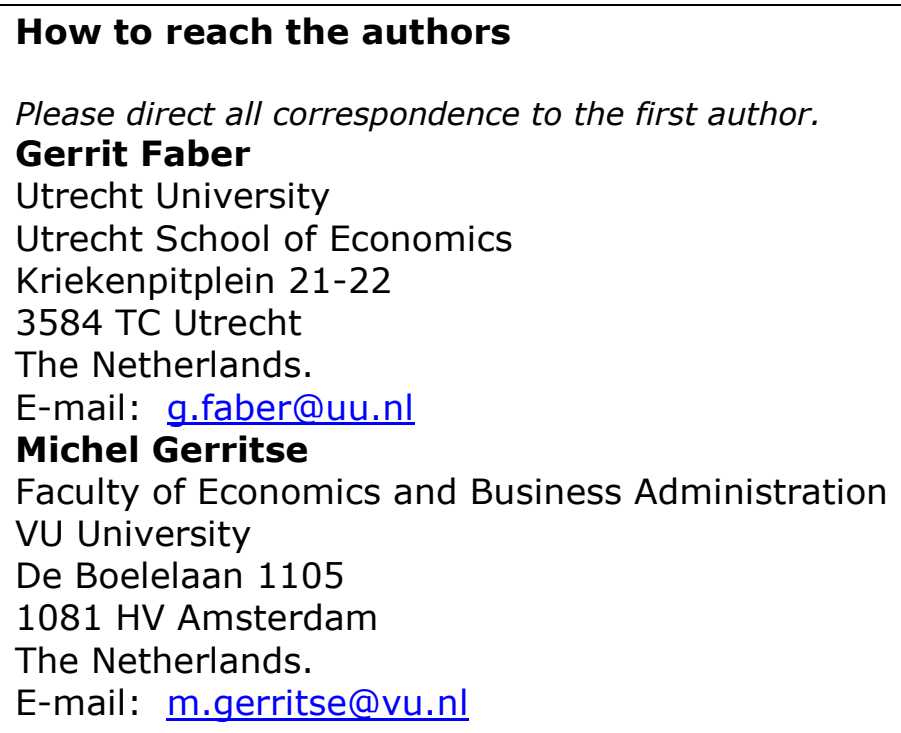




\title{
Deep determinants or interactions: explaining spatial patterns in human rights
}

\author{
Gerrit Faber ${ }^{a}$ \\ Michel Gerritse \\ aUtrecht School of Economics \\ Utrecht University \\ ${ }^{\mathrm{b}}$ Faculty of Economics and Business Administration \\ VU University \\ October 2012
}

\begin{abstract}
The respect for human rights follows strong spatial patterns among countries. However, to understand and predict the spatial effects of policies and interventions, it is imperative to know whether these spatial patterns stem from countries' interactions and spillovers, or from common deep determinants, such as history and physical geography. This paper makes an effort to disentangle the two. The lion's share of spatial patterns is accounted for by time-invariant factors, while the evidence of contemporaneous spillovers is very marginal. This limits the scope of regional effects when individual countries change their human rights situations.
\end{abstract}

Keywords: interaction and spillovers, human rights, spatial econometrics, institutions

JEL classification: C23, F53, K33, O19 


\title{
Deep determinants or interactions: explaining spatial patterns in human rights
}

Gerrit Faber $^{\mathrm{a}}$ and Michiel Gerritse ${ }^{\mathrm{b}}$

\begin{abstract}
The respect for human rights follows strong spatial patterns among countries. However, to understand and predict the spatial effects of policies and interventions, it is imperative to know whether these spatial patterns stem from countries' interactions and spillovers, or from common deep determinants, such as history and physical geography. This paper makes an effort to disentangle the two. The lion's share of spatial patterns is accounted for by timeinvariant factors, while the evidence of contemporaneous spillovers is very marginal. This limits the scope of regional effects when individual countries change their human rights situations.
\end{abstract}

JEL classification: C23, F53, K33, O19

Keywords: interaction and spillovers, human rights, spatial econometrics, institutions

\footnotetext{
${ }^{\text {a }}$ Utrecht University School of Economics, P.O. Box 80125, 3508 TC Utrecht, The Netherlands. G.Faber@uu.nl

${ }^{\mathrm{b}}$ Faculty of Economics and Business Administration, VU University, De Boelelaan 1105, 1081 HV Amsterdam, The Netherlands. m.gerritse@vu.nl
} 


\section{Introduction}

A country's location on the globe is likely to have an effect on the domestic respect for human rights. As foreign investors care for their reputation, countries that have better human rights records are preferred to other candidates in the region, all else being equal. Aid donors are likely to give more support to recipients that have a better human rights performance than countries with the same development problems. And as most countries will try to reproduce their domestic values beyond their borders, it may be expected that countries respond to a serious deterioration of the respect for human rights in their neighbors by exerting political pressure or by introducing economic or military sanctions. The same effect may be brought about by the impact of civil conflicts in adjacent nations that inflict economic hardship or lead to an inflow of large numbers of refugees, as a result of which the domestic respect for human rights is likely to suffer. As a result, there are forces of spatial convergence in the rate of human rights infractions among adjacent countries.

The spillover effects among adjacent countries can work in two directions - towards improving or deteriorating human rights records in a region. As a result, regional clusters of countries with comparable human rights records will materialize. Figure 1a shows a map that summarizes counties' scores on the U.S. State Department human rights index. Visually, there is indeed a clustering of high and low scores.

However, a country's respect for human rights is also likely to be determined by its history and geography. Such "deep determinants" originate from the factors that also influence the country's long run economic, political and institutional development, and typically cannot be manipulated. Thus, a large literature argues that the resources and physical geography found in Sub-Saharan Africa are at the source of institutions that hamper development (Sachs 2001). These institutions are likely to contribute to violent conflicts, which are characterized by substantial human rights violations. Similarly, human rights records have a close correlation with per capita national income, which in turn, is strongly influenced by the institutional origins at the start of the modern age (Acemoglu c.s. 2001, idem 2002, idem 2005 and Rodrik c.s. 2004).

The issue that this paper addresses is relevant for policy discussions as well. If we are to expect any results from policies that aim to change countries' human rights records, and in particular if such intervention is presumed to have wider benefits across the region, then the spatial patterns must be caused, at least in part, by current interaction effects. If the deep 
determinants account for the full explanation of spatial human rights patterns, then it is unrealistic to expect any spatial spillovers from improved human rights situations. In that case, similarities to neighboring countries are based on sharing climate, diseases, legal heredity, or soil quality through proximity, and improvements in human rights attitudes are unlikely to spread out to other countries.

Here figure $1 \mathrm{a}$ and $1 \mathrm{~b}$.

The essence of the analysis of this paper is captured in Figure 1b. This map plots the changes of the human rights scores throughout the world, rather than scores' levels. Eyeballing reveals less of a spatial pattern compared to Figure 1a. If deep determinants are the main driver of the similarity of human rights within large regions or continents, then their impact should show up in relatively little variation over time: the effects of geography and history do not change overnight. Vice versa, if we compare changes in countries' human rights scores over time (a decade), strong spatial patterns in such changes imply that proximate countries' human rights situation evolve similarly. This effect in changes cannot be attributed to deep determinants, given that deep determinants do not cause short-run changes. In other words, the long run effects that are captured in the human rights scores' levels are filtered out if we examine how changes in human rights situations coincide spatially. Therefore, a spatial co-evolution of human rights is consistent with spillovers in the respect for human rights, whereas spatial patterns solely in the average human rights scores points to other causes of spatial patterns, such as those in the distant history. A statistical test of the spatial independence of the scores in levels (Figure 1a) rejects that they are randomly distributed over space: the Moran's I based on inverse distances is 0.123 , with a p-value beyond the second decimal. In contrast to this, a Moran I test cannot reject a random distribution over space of a decade's change of scores (Moran's I of 0.005, p-value of 0.22). Thus, at first glance spatial spillovers in human rights scores appear to be weaker than fundamental long-term determinants. In the rest of this article we test this proposition.

Through this line of analysis, the paper contributes to a strand of literature investigating policy interactions in political and institutional outcomes, most notably in institutional 
quality. Kelejian et al. (2008) and Faber and Gerritse (2012) are examples that document significant effects of the institutions in nearby countries on domestic institutional quality, such as the rule of law, voice and accountability and control of corruption. In contrast to this literature, however, this paper disentangles the causes of spatial patterns in spatial correlations in the long-run determinants and in contemporaneous interaction effects.

The paper also contributes to the literature of determinants of human rights violations. Individual mechanisms that could explain proximity-effects in human rights have been investigated in the literature, such as sensitivity to foreign direct investments (Blanton and Blanton 2007), aid flows (Carey 2007), or regional agreements on human rights (Hathaway 2002). However, to our knowledge, this paper is the first to document the statistical spatial correlations in human rights indicators.

The paper is organized as follows. In the second section, we discuss the plausibility of two explanations for the spatial clustering of human rights records over the globe: spatial interaction effects in human rights scores that operate in the present and may change rapidly; and determinants that have a strong stability over time. The third section lays out the empirical strategy and the descriptives of our dataset. Section four presents the results of the empirical analysis; a discussion of our results in section five completes the paper.

\section{Deep determinants or spatial spillovers?}

\section{Deep determinants}

Human rights are part of a broader set of rules and laws. As such, human rights are part of the institutions that Douglas North (1991) defines as "the humanly devised constraints that structure political, economic and social interaction. They consist of both informal constraints (..) and formal rules (..).". We consider human rights to be political institutions (like democracy) because they act as constraints on political actors and have an impact on the ability of individuals to organize opposition against the established powers. The human rights records of countries is indeed strongly linked to political institutions such as democracy (Cingranelli and Richards 1999; Landman 2005). If the established powers in a nondemocratic setting are afraid that their real ('de facto') power might be diminished, a civil conflict may arise that may lead to violations of the human rights of the opposing groups. Human rights are also analyzed as the result of economic institutions. Mousseau and Mousseau (2008) argue that in societies where contract terms are determined by in-group 
reciprocity, individuals are loyal to the group (extended family, feudal system, band, etc.) and its leaders and support the beliefs and values that are predominant in the group. In nations that have a 'market place society', there are "widespread social routines based on respect for the choices of individuals, the equal rights of strangers, the formation of secular and impartial governments, and the rule of law and contracts" (Mousseau and Mousseau, 2008: 332). According to this 'economic norms theory', individuals in a market place society are dependent on the state and need governments that do not discriminate among individuals and respect the rule of law. In a society where reciprocity in the group is the source of trust, there is less support for the idea that the rights of 'the others' are equal to 'our' rights. The authors find strong empirical support for the hypothesis that the contract-intensiveness of an economy has an important influence on the extent of state repression.

Recent work to unravel the long run or deep determinants of economic development of nations is relevant for the explanation of differences in human rights records as well. Two schools of thought can be distinguished: the 'new institutionalists' and the scholars who stress the geography of countries. The latter school maintains that physical geographical factors are the main determinants of growth and development. Gallup et al. (1999) find that in a long run perspective the growth rates in tropical regions are lower as a result of higher disease burdens and a lower productivity in agriculture, while regions that have easy access to sea transport are better placed for higher growth rates than inland regions, and this applies even stronger for land-locked countries. Sachs (2001) argues that technological development is strongly geared towards increasing productivity in temperate zones. Some geographical variables have a direct impact on institutions, including human rights (Acemoglu et al. 2001, see below). There is also an indirect influence through economic development: higher per capita incomes increase the demand for better institutions.

Acemoglu et al. (2005), representatives of the new institutionalist approach, argue that economic institutions are crucial for the long run development of societies. By shaping the economic incentives, they affect present-day outcomes like the distribution of resources, for instance via (earlier) investment in physical and human capital. However, as Acemoglu et al. argue, the economic institutions are determined by the present and historical distribution of political power over groups in society. Therefore, the economic and political incentive structures that evolved in history are likely to determine current outcomes. Historical and statistical research has confirmed these hypotheses by showing that, e.g., the kind of colonization at the beginning of modern history is an important explanatory variable for 
present day political and economic institutions (Acemoglu et al. 2001 and 2002; Rodrik et al. 2004). Geographical factors may influence the present institutional quality of societies by the effect on the colonial systems European countries introduced centuries ago.

The upshot is, that there are good reasons to expect that the political and economic institutions of a country - including the respect for human rights - are determined by forces that are relatively constant over time, as geographical factors are close to invariable over time by definition while groups that are in command of most of the political power have the means to stay in power over long periods.

\section{Spatial spillovers}

Spatial correlations in policy outcomes are a pervasive pattern. One of the first studies to document spatial dependencies in policy is Easterly and Levine (1998), who show that imitation is an important determinant of policy in sub-Saharan African countries. Kelejian et al. (2008) study spatial spillovers between countries in the development of institutions. In a panel data setting, they explain the quality of economic institutions from institutions in bordering countries. These authors find that spatial spillover effects are a significant explanation for institutional quality. In order to compare the explanatory power for local institutional quality of openness to trade and investment and spatial dependence, Faber and Gerritse (2012) use a 107-country cross-section and find that both trade openness and relative location have a positive impact on local institutions.

The location of a country relative to other countries has an impact on the costs and benefits of changing the national human rights record. Or, in different words, the choices that adjacent countries make with respect to their human rights performance have an impact on the decisions that governments make with respect to this subject. In a comparable approach for economic institutions, Simmons and Elkins (2004) propose two broad mechanisms for spatial spillovers. First, a choice for particular institutions elsewhere will change the payoffs of these institutions for domestic policymakers. Applied to our subject, an improved human rights performance in the region will constitute an incentive for a national government to move in the same direction, as there exists competition with governments of adjacent economies for development aid, foreign direct investment and highly skilled workers. Multinational firms generally decide first to invest in a particular region (to exploit the available human and natural resources or to serve local or regional markets). The second step is to decide exactly where to locate and how much to invest (Navaretti and Venables, 2006). It is plausible that at this stage of decision-making, the human rights records of the countries concerned are taken 
into account. A comparable policy competition has been found among Chinese regions. Du c.s. (2008) find that US multinationals investing in China prefer regions that have better economic institutions (such as better protection of intellectual property rights and lower levels of government corruption). Luo et al. (2008) find the same result for policy incentives in Chinese regions. Thus, it is plausible to hypothesize that the human rights performance is an element in the policy competition among countries in a region for FDI as these investors care for their reputation. Blanton and Blanton (2007) find strong support for their hypothesis that a good human rights record is a locational advantage to attract foreign investors. We therefore argue that the respect for human rights is endogenous and can be manipulated by policymakers. Potentially, human rights records could then be the outcome of policy competition among neighboring countries, making the HR situation in neighboring countries a determinant of the domestic HR performance. The reverse mechanism could also hold: those countries that permit violations of human rights could attract FDI if this implies cost advantages. Although there is anecdotal evidence that this is indeed occurring, most empirical research points in the other direction (Blanton and Blanton 2007). The main explanation given is that in recent times, FDI has been concentrated in producing and marketing consumer goods, manufacturing and services, which are exposed to public monitoring with respect to the corporate governance of multinational firms and their subcontractors.

Competition for development aid may also be a reason for policy competition. As most donors have a predetermined amount available for aid, while they concentrate their aid on the poorest countries that are geographically concentrated, poor countries are competing for these funds. Many donors of aid claim that respect for human rights plays a role in the decision on the distribution of development aid. However, a recent analysis of European donors by Carey (2007) shows that the human rights records of the aid candidates do not influence the decision which countries will receive aid. Bureaucratic inertia and poverty are more important factors in all stages of decision making. In their study on US aid allocation, Demirel-Pegg and Moskowitz (2009: p. 96) find that after the end of the Cold War human rights gained a somewhat larger role in the country selection stage. At the same time they say that '... perhaps our most distinct finding is that the USA holds neither underdeveloped nor transitioning regimes accountable to high human rights standards'. The main exception are autocratic states: those that have better human rights records get more aid than those with bad records. Lebovic and Voeten (2009) test the hypothesis that a developing country that has been criticized in a resolution by the United Nations Commission on Human Rights (UNCHR), will receive less aid. These authors find that such countries do indeed get 
significant lower World Bank and multilateral loan commitments, but that bilateral aid allocations are not affected. From these empirical findings it may be concluded that the human rights records of aid receiving countries play a minor role if at all in the distribution of development aid, making policy competition a rather weak mechanism in this area.

The second mechanism of spatial spillovers in HR performance is the effect that the institutional quality in neighbouring countries 'can change the information set on which governments base their own policy decisions' (Simmons and Elkins 2004). If many countries in the region have a low respect for HR, a government that is in conformity with its neighbors does not suffer reputational damage from a low HR performance. However, if there is a growing consensus to improve the HR situation in a relevant group of countries, defecting will give rise to reputational damage. Policy failures in this country may be blamed to nonconformity to the regional consensus, which puts the government in an isolated position. In addition, there is a learning effect as governments and citizens get information about the effects of different human rights situations in countries they consider as their reference group. We hypothesize that the reference group consists of countries in the region. In the case of human rights this is a plausible assumption, as there is a continental emphasis in the HR Agreements and courts. The African Court on Human and Peoples' Rights rules on the basis of the African Charter on Human and People's Rights that came into force in 1986. The states of the American continent agreed on the American Convention on Human Rights in 1969, and created the Inter-American Commission on Human Rights and the Inter-American Court of Human Rights. The European Court of Human Rights was created in 1950 and is linked to the European Convention on Human Rights. ${ }^{1}$ Asia and the Middle East do not have comparable agreements and courts. Shelton (1999: 365) argues that regional homogeneity has 'fostered a sense of trust among the member states that has made them sometimes less sensitive to criticism of their human rights performance.' As a result, regional courts are said to have had a positive impact on the respect for human rights. However, a different result was obtained by Hathaway (2002) who found that ratification of human rights treaties is often associated with a deterioration in human rights performance and that this applies in particular for regional treaties.

\footnotetext{
${ }^{1}$ These charters and courts differ, although all member states of the United Nations are bound by the Universal Declaration on Human Rights of 1948. E.g. only the European Court is open for individuals.
} 


\section{Empirical strategy and data}

\section{Estimation strategy}

To investigate to what extent the respect for human rights is directly affected by the human rights outcomes in nearby countries, we specify a statistical model that accounts for the effect of peer countries' human rights infractions on the local human rights performance.This effect is captured by augmenting a linear regression with a variable that is referred to as a spatial lag. It summarizes the state of human rights in other countries, where a pre-specified weighting scheme assigns higher weights to nearby countries.

The spatial lag allows us to consider if there is a direct statistical association in human rights scores between geographically proximate countries. Using the inverse of distance between capitals as a weights measure, and $Y$ as the human rights score, the spatial lag is $\sum_{i \neq j} w_{i j} Y_{j}$. In effect, this variable is a cross-sectional average of peer countries' human rights scores, where the weights for nearby countries are larger than those of distant countries. We standardize the weights, i.e. require that they sum to one for all peers: $w_{i j}=$ dist $_{i j}{ }^{-1} / \sum_{i}$ dist $_{i j}^{-1}$. This allows us to specify a spatial linear regression model for a panel where $i$ and $t$ denote the cross-sectional and time dimension as follows:

$Y_{i t}=\lambda \sum_{i \neq j} w_{i j} Y_{j t}+\sum_{k} \beta_{k} x_{k i t}+\alpha_{i}+\varepsilon_{i t},(1)$,

where $x_{k i t}$ refers to the control variables indexed by a $k$. The term $\alpha_{i}$ captures the timeinvariant, country-specific effects on the local human rights score index. To obtain estimates on the relevant parameters in equation (1), a number of additional issues needs to be addressed.

Firstly, as we argued, there are several processes that could explain spatial patterns in human rights indicators, and we are specifically interested in sorting out contemporaneous (interaction) effects from long-run effects. Insofar as spatial patterns in human rights indicators are driven by the variables in the controls, they do not appear as spatial patterns. It is well plausible, though, that the shocks, which are supposedly independent, have a spatial component. For instance, climatic events, political unrest or other economic circumstances could indirectly affect the human rights indicators in a similar manner if two countries are proximate. That could give rise to patterns that look like 'spillovers', but are in fact caused by omitted variables and shocks, which appear in the error term. To accommodate such 
processes, we shall explicitly allow the error term to follow spatial processes, such that: $\varepsilon_{i t}=\rho \sum_{i \neq j} w_{i j} \varepsilon_{j t}+u_{i t}(2)$,

where $u_{i t}$ is an IID error term.

Similarly, it is likely that countries that share borders or are nearby to each other also share a history and have a similar geography. Much of the literature on institutions and policy points to a role of earlier developments in modern history such as industrialization, political development, colonization and the blessings and curses of resource abundance and accessibility as determinants of policy outcomes and the respect for citizens. Therefore, it is quite likely that such features, which exhibit strong spatial patterns, determine current attitudes toward human rights. However, if we are interested in the question how changing respect for human rights by neighbors affects local changes in outcomes, the effects of common history and geography play no role. In order to address this issue, we exploit the within-variation of the sample, and allow the fixed effects $\alpha_{i}$ to pick up time-invariant effects. The time-invariant effects can be eliminated from the model estimating the model in differences from the time-average. Using $\bar{x}_{i t}=x_{i t}-1 / T \sum_{t}^{T} x_{i t}$ as the within-variation in a variable, the fixed effect model can be written as:

$\bar{Y}_{i t}=\lambda \sum_{i \neq j} w_{i j} \bar{Y}_{j t}+\sum_{k} \beta_{k} \bar{x}_{k i t}+\rho \sum_{i \neq j} w_{i j} \bar{\varepsilon}_{j t}+\bar{u}_{i t}$

Where the time-invariant effects are filtered because $\bar{\alpha}_{j}=0$. Therefore, the specification with fixed effects eliminates the effects of deep determinants, isolating contemporaneous interactions.

Equation (3) cannot be estimated by regular OLS. There is a simultaneity bias in the spatial lag, because if outcomes in $i$ affect $j$, it is also likely that the reverse occurs. To account for this reflection effect, we use a maximum likelihood estimator that takes the explicit structure of the spatial interaction into account. Additionally, the presence of fixed effects in this model renders the variance-covariance matrix singular, which requires a modification of the loglikelihood function to circumvent this issue. We follow the transformation approach of Lee and Liu (2010), and use an adapted likelihood function (Lee and Liu 2010, equation 7).

\section{Descriptive statistics}

Table 1 presents the descriptive statistics of our sample, which runs over the years 1999-2009 and over 146 countries. For the human rights performance of countries we use the Political 
Terror Scale (PTS) as published by Gibney at al. (2010). We use the scores published by the US State Department. Countries are scored on a five-point scale with respect to use by the state of extra-judicial killings, torture, political imprisonment and exile (Gibney at al. 2010; Landman and Carvalho 2009). Higher scores points to a poorer human rights performance. The data on the onset of conflict stem from the Peace Research Institute in Oslo. ${ }^{2}$ All other controls are from the World Bank open data initiative. ${ }^{3}$ Note that time invariant variables, like climate, do not contribute to the within-variation, because they are subsumed in the fixed effects, and therefore controlled for. Throughout the paper, we use bilateral distances, which are from the CEPII dataset. A Moran's I test for spatial autocorrelation is given in the fourth column. The statistic is based on inverse distance, and shows strong spatial autocorrelation for all variables.

The selection of controls is based on a reading of the literature that statistically explains human rights levels. Following Poe and Tate (1994), Lee et al. (2002), Landman (2005) and Hafner-Burton (2005) we include variables that describe economic welfare, population size and conflicts in the country. Because we have a large share of developing countries in our dataset we also include urbanization rates and life expectancy, which vary widely in terms of development. Also, as the onset of conflict may be traced back to food shortages or the presence of appropriable resources, we include a food production index and the natural resource rents as a share of GDP. As a variable describing the quality of economic policy we use a traditional measure of policy quality, inflation. In addition to these, the literature offers many variables that describe initial conditions, such as colonial history, language, ethnolinguistic features, judicial and political systems. Note that these are generally timeinvariant, and thus are absorbed in our fixed effects specification.

Here Table 1

The statistical model smoothes out time-invariant effects, which potentially account for the largest share of the identification. In particular, little variation over time within countries relative to variation between countries (cross-sectional) could render unstable fixed effects estimates and reduce comparability between the regular and fixed effects models. To

\footnotetext{
${ }^{2}$ Freely available from http://www.prio.no/CSCW/Datasets/Armed-Conflict/

${ }^{3}$ Accessible via http://databank.worldbank.org/data/home.aspx
} 
investigate this possibility, we have calculated the cross-sectional variation for each year; the average cross-sectional standard deviation in the human rights score is 1.08. The average standard deviation over time within each country is 0.44 . $\mathrm{So}_{2}$ while the average crosssectional variation is clearly larger, the average within (country over time) variation is still substantial.

\section{Results}

Table 2 reports several regressions results that have the country scores on the PTS as dependent variable. A baseline regression (pooled OLS, column 1) shows that the signs of the coefficients are as expected, and all are statistically significant. When eliminating fixed effects from the data, several controls turn statistically insignificant. Most notably, all except the life expectancy and conflict variables are statistically no longer significant. This suggests that the majority of controls is determined in the long run or is closely associated to unobserved time-invariant variables. Column three presents a pooled regression with a spatial lag. It is estimated using the standard maximum likelihood functions. Since we use a pooled specification, it is not surprising that the point estimates on the controls are of similar magnitude to those reported in column 1 (pooled OLS). The spatial lag is statistically significantly different from zero.

Here Table 2

Most importantly, the fourth column reports the fixed effects specification with a spatial lag and potential spatial autocorrelation in the error term, estimated under the log-likelihood function derived in Lee and $\mathrm{Yu}$ (2010). Again, the point estimates are rather similar to the case without a spatial lag, although the comparison here is with the OLS fixed effects specification instead of the pooled equation. However, unlike in the pooled case, adding a spatial lag to the regression does not yield a statistically significant coefficient on the spatial lag. Therefore, once fixed effects are controlled for, there seems to be not much evidence of spatial interaction effects.

In line with most literature dealing with human rights indicators, we have used the PTS as if it is a cardinal scale. Even though the scale has been constructed on the assumption that moving 
'from score 2 to 3 is the same as a move from a score of 4 to 5' (Landman and Carvalho 2009: 76), the PTS basically is an ordinal scale (Wood and Gibney 2010). This problem is circumvented in part by the use of fixed effects regressions that look at the deviations from averages. Therefore, the initial level of human rights is accounted for in the fixed effects. A more ideal way of addressing this issue would be to estimate a multinomial logit model, but that cannot (yet) be combined with a fixed effects spatial lag model. A consistent but less efficient alternative is to divide the scores into 'high' and 'low' scores. This allows the above model to be interpreted as a linear probability model, which does not suffer the cardinality issue. Even if this ignores much of the variation in outcomes, the results persist. Columns 5 and 6 of Table 2 repeat the exercise, where the dependent variable is transformed. In particular, all observations for which the human rights score is assigned a 1 or 2 are transformed to a 0 . All scores above 2 are transformed into a 1 . Using this, around 49 per cent of the data fall into the low score class. The model gives the effect of each of the variables on the conditional probability of being in the class of high scores. As can be discerned, the fixed effects transformation has significant effects on several of the controls. More importantly, the spatial lag is statistically significant in the pooled case, but not in the fixed effect case. This result in the linear probability model is consistent with the results in the 'cardinal' model. Therefore, ignoring the ordinal nature of the data does not seem to affect our conclusions. It must be noted, however, that there are potential sample selection effects. In the fixed effects specification, time invariant variables are filtered out, so the coefficients are identified based on human rights scores that vary over time. Clearly, when moving from five to two categories, the odds of a country switching category fall, and the group of countries responsible for the identification could be smaller in the two category case.

It might be that some of our controls are endogenous. For example, while we are assuming that GDP and conflicts affect behavior of political leaders in charge, we cannot rule out that lower human rights scores hamper economic growth or cause conflict. Unfortunately, there are no maximum likelihood estimators that extend the spatial lag model to address the endogeneity of variables. However, we have excluded the variables that are most likely to generate endogeneity problems (GDP, conflict, inflation) and rerun the regressions. The results are reported in column 7 , and show a slightly increased estimate of the spatial lag, but it is still insignificant. Hence, the potential endogeneity does not seem to affect our conclusions. Using instrumental variables as an alternative strategy to address the endogeneity of the spatial lag could allow taking into account other endogeneity issues. However, based on the standard instruments (spatially lagged controls), the coefficient of the spatial lag is very 
imprecisely estimated, with high standard errors and unstable coefficient estimates. In the fixed effects model, most controls poorly predict the human rights record, and it seems that lagged controls therefore make for weak instruments (instrument relevance tests are low).

It is plausible that the average coefficient on the spatial lags masks significant heterogeneity in the spatial patterns. If only a small enough share of the sample has significant interaction patterns, the full sample specification may not pick these up. Since the interaction effects are most likely local, it is most logical to divide the sample in geographical areas, and check the stability of the coefficients for each of the subsamples. Following the World Bank classification of geographical zones, we have divided the sample in: i) Latin America and the Caribbean, ii) Europe and Central Asia, iii) Sub-Saharan Africa, North Africa and the Middle East, and iv) Asia. Table 3 presents the same regression specification as in column 6 of Table 2 for each of these subsamples.

\section{Here Table 3}

Table 3 shows that while there is substantial heterogeneity in the controls, in the fixed effects specification no significant coefficient on the spatial lags is found. This suggests that it is unlikely that heterogeneity in the spatial dynamics masks any significant effects in the full sample. In each of these subsamples, the specification without fixed effects leads to significant estimates on the spatial lags, as in the full sample ${ }^{4}$. Interestingly, urbanization mostly seems to affect human rights in European countries, but less so in Asia, Africa and Latin America. Conflicts have significant positive effects on human right scores in all of the subsamples, except in Latin America. Looking at Africa, the only statistically significant control is our conflict variable, while the controls do not seem to perform all that well in Latin America. ${ }^{5}$

The maximum likelihood is derived under the assumption that disturbances are normally distributed. A test of this assumption (Jarque-Bera) shows that the kurtosis of the errors leads to a rejection of the null that the kurtosis is consistent with a normal distribution; the excess kurtosis in the full sample is 0.507 (skewness 0.015 ). Non-normality is not surprising in our sample, because, if nothing else, the dependent variable's range is restricted, and the

\footnotetext{
${ }^{4}$ Spatial lag coefficient estimates in pooled case for Latin America: 0.24 (s.e. 0.09), Europe: 0.37 (s.e. 0.07), Africa: 0.21 (s.e. 0.09), Asia: 025 (s.e. 0.08).

${ }^{5}$ Note that there is a residual World Bank category of "Industrial countries" that have overlap and are widely geographically spread.
} 
incidence of conflict variable hardly follows a normal distribution. The leptokurtic distribution, however, suggests we underestimate the standard errors, rather than overestimate them, which would increase the probability of type I errors. Therefore, we would be more, rather than less likely to find a statistically significant spatial lag. In part, the non-normality also seems to be driven by sample heterogeneity, as in all subsample estimations, the null that the disturbances are normally distributed cannot be rejected (in the Asian sample, we estimate the model in logs, where incidence, inflation and urban population are not transformed). Since our findings are consistent throughout the subsamples, the non-normality of the errors does not seem to affect our conclusions much. For visual inspection, a plot of the regression disturbances is added in the Appendix.

Finally, we investigate to what extent our assumptions on the spatial correlation pattern are responsible for the results. A drawback of using the spatial econometric model is that the spatial decay structure must be imposed ex ante. The researcher can only test the magnitude and statistical significance of spatial correlations given the weights assigned to bilateral relations, which are then used in the weights matrix. So far, we have used inverse distance to define the bilateral weights: $w_{i j}=1 /$ dist $_{i j}$. In the spatial econometrics literature, this is a very common way of modeling spatial decay patterns. Using inverse distance as weights gives a power law of spatial decay, where a doubling of distance implies that the weight is halved. A more general form would be $w_{i j}=1 /$ dist $_{i j}{ }^{\alpha}$, which allows varying the decay effects. Setting $a=1$ gives the inverse distance, but setting $a>1$ allows for a more rapid decay of spatial effects over distance. However, such a decay parameter cannot be estimated in the spatial econometric model, because it is used in the construction of the spatial weights matrix. To investigate the sensitivity of the model to the assumptions of the decay pattern, we have reestimated the model for different values of the decay parameter a, starting from 0.5 and adding 0.5 for each consequent step (up to $a=4$ ). The resulting estimates on the spatial lag obtained in the fixed-effects specification, and their corresponding confidence intervals are summarized in Figure 2. Additionally, this Figure reports the overall Wald test for the complete model, as a measure of the fit of the equation.

\section{Here Figure 2}


Figure 2 shows that increasing the decay parameter compared to inverse distance $(a=1)$ does not lead to substantial changes in the point estimate of the spatial lag. However, for $a=1.5$, the lag is slightly higher and estimated slightly more precise, leading us just to reject that the lag coefficient is zero. This model also shows a better fit than others, as witnessed by higher Wald-statistics. Lowering the decay parameter (allowing for spatial effects to decay less rapidly) decreases the model fit and increases the standard errors of the estimate of the spatial lag. Given the sample size (1610), searching along the decay parameter space thus leads to a marginally statistically significant spatial lag at the $5 \%$ level.

\section{Discussion of the results and conclusion}

This paper tests for spatial dependence between countries in human rights performance. It reports significant spatial correlations in human rights scores. It uses the time dimension of the panel to disentangle the contemporaneous interaction effects from the (long-run) time invariant effects. When the latter effects are eliminated from the regression, the evidence for interaction effects are virtually absent.

These results suggest that deep determinants are the main shaping force of spatial patterns in human rights performance, while interaction effects play only a minor role. The timeinvariant factors, related to history and physical geography account for most of the variation in outcomes. A hypothesized second set of causes stems from interaction effects. These include the pressure from peer countries' human rights records when competing for international (direct) investments or foreign aid. These interaction effects, however, find only marginal support in the data.

Apparently, on average countries do not respond to their neighbors' human rights performance, or at least take a very long response time. This statistical finding is inconsistent with the idea that countries can easily be pressured from the outside to change their respect for human rights. Likewise, for donors and development organizations seeking to improve human rights records in a region, the external effects of bilateral action seems limited. We do want to note, however, that the analysis looks at average effects, which implies that there will be particular cases where outcomes can differ, such as for countries in severe conflict.

The conclusions are robust to changes in the model specification: dropping potentially endogenous variables, addressing the non-cardinal scale of the PTS scores and subsample heterogeneity. The construction of a spatial lag ex ante requires imposing some form of decay 
pattern, which is restrictive. The results are somewhat sensitive to the choice of decay parameter, as searching the decay parameter space shows that spatial lags can be constructed to provide marginal statistical evidence of interaction effects. An additional consideration is that a sample period of more than ten years might be better if interaction effects occur slowly. However, given the length of investment contracts and the length of political cycles, one would expect the effects of policy competition or changed information sets to materialize to some extent. Moreover, the variation in human rights score over time is substantial compared to the variation over the cross-section, so it seems likely that interaction effects would surface. Lastly, the substantial difference in conclusions that emerges from using the fixed effect model and the pooled model has significant methodological implications. In research studying long-run developments like institutional change, a growing literature uses spatial lags in cross-sectional or pooled analyses to assess interaction effects. Our results show that spatial heterogeneity can easily be mistaken for interaction effects, which is a very different process.

\section{References}

Acemoglu, D., Johnson, S. and Robinson, J.A. (2001) 'The Colonial Origins of Comparative Development: an Empirical Investigation' in: American Economic Review, 91(5): 1369-1401.

Acemoglu, D., Johnson, S. and Robinson, J.A. (2002) 'Reversal of Fortune: Geography and Institutions in the Making of the Modern World Income Distribution' in: Quarterly Journal of Economics, 117(4): 1231-1294.

Acemoglu, D., Johnson, S. and Robinson, J.A. (2005). 'Institutions as the fundamental cause of long-run growth' in: Aghion, P. and Durlauf, S.N. (eds), Handbook of Economic Growth, Vol. 1, Amsterdam: Elsevier, 385-472

Alesina, A., Baqir, R. and Easterly, W. (1999) 'Public goods and ethnic divisions' in: Quarterly Journal of Economics, 114: 1243-1284.

Alesina, A. and La-Ferrara, E. (2000) ' Participation in heterogeneous communities' in: Quarterly Journal of Economics, 115: 847-904. 
Arts, K. (2009) 'A human-rights-based approach to the ACP-EU EPAs: issues and implications', in: Faber, G. and Orbie, J. (eds) Beyond Market Access for Economic Development. EU-Africa relations in transition', Abingdon and New York: Routledge, 279304.

Blanton, S.L. and Blanton, R.G. (2007) 'What attracts foreign investors? An examination of human rights and foreign direct investment' in: The Journal of Politics, 69 (1): 143-155.

Burkhart, R.E. (2002) 'The capitalist political economy and human rights: cross-national evidence' in: The Social Science Journal, 39: 155-170.

Carey, C.C. (2007) 'European aid: human rights versus bureaucratic inertia' in: Journal of Peace Research, 44(4): 447-464

Cingranelli, D.L. and Richards, D.L., (1999) 'Respect for Human Rights After the End of the Cold War' in: Journal of Peace Research, 36(5): 511-534.

Demirel-Pegg, T. and Moskowitz, J. (2009) 'US aid allocation: the nexus of human rights, democracy, and development' in: Journal of Peace Research, 46(2): 181-198.

Du, J., Lub, Y. and Tao, Z. (2008) 'Economic institutions and FDI location choice: evidence from multinationals in China' in: Journal of Comparative Economics, 36(3): 412-429.

Easterly, W. and R. Levine (1998) 'Troubles with the neighbours: Africa's problem, Africa's opportunity' in: Journal of African Economies, 7(1): 120-142.

Faber, G. and Gerritse, M. (2012) 'Foreign determinants of local institutions: Spatial dependence and openness' in: European Journal of Political Economy, 28(1): 54-63.

Gallup, J.L., Sachs, J.D. and Mellinger, A.D. (1999) 'Geography and economic development', in: Regional Science Review, 22179 -232. 
Gibney, M., Cornett, L., \& Wood, R., (2010) Political Terror Scale 1976-2010. Data and description retrieved from the Political Terror Scale Web site: http://www.politicalterrorscale.org/ (accessed 3 August 2012)

Hathaway, O.A. (2002) 'Do Human Rights Treaties Make a Difference?' in: The Yale Law Journal, 111 1935-2042.

Hafner-Burton, E.M. (2005) 'Right or robust? The sensitive nature of repression to globalisation' in: Journal of Peace Research, 42(6): 679-698.

Howard-Hassmann, R.E. (2005) 'The Second Great Transformation: Human Rights Leapfrogging in the Era of Globalization' in: Human Rights Quarterly, 27: 1-40.

Kaufmann, D. (2005) 'Human Rights and Development: Towards Mutual Reinforcement', Paper, New York: New York University School of Law, 26 p.

Kaufmann, D. and Kraay, A. (2002) 'Growth without Governance' in: Economia, 3(1) 169229.

Kelejian, H., Murrell, P. and Shepotylo, O. (2008) 'Spatial spillovers in the development of institutions'. Available at SSRN: http://ssrn.com/abstract=1031974 or http://dx.doi.org/10.2139/ssrn.1031974

Landman, T. (2005) 'Review Article: The Political Science of Human Rights' in: British Journal of Political Science, 35: 549-572.

Landman, T. and Carvalho, E. (2009) Measuring Human Rights, London and New York: Routledge.

Lebovic, J.H. and Voeten, E. (2009) 'The cost of shame: international organizations and foreign aid in the punishing of human rights violators' in: Journal of Peace Research, 46(1): 79-97. 
Lee, C., Lindström, R., More, W.H. and Turan, K. (2002) Ethnicity and repression: the ethnic composition of countries and human rights violation, Florida State University (http://mailer.fsu.edu/ whmoore/garnet-whmoore/research/Leeetal.pdf, accessed 3 August 2012)

Lee, L-F. and Yu, J. (2010) 'Estimation of spatial autoregressive panel data models with fixed effects' in: Journal of Econometrics, ??? 165-185.

Li, Q. and Resnick, A. (2003) 'Reversal of fortunes: democratic institutions and foreign direct investment flows to developing countries' in: International Organization, 57(1): 175-211.

Luo, L., Brennan, L., Liu, C. and Luo, Y. (2008) 'Factors influencing FDI location. Choice in China's Inland Areas' in: China \& World Economy, 16(2) 93-108.

Mitchell, N.J. and McCormick, J.M. (1988) 'Economic and political explanations of human rights violations' in: World Politics, 40(4): 476-498.

Navaretti, G.B. and Venables, A. (2006) Multinational Firms in the World Economy. Princeton University Press, Princeton, NJ.

Mousseau, M. and Mousseau, D.Y. (2008) 'The Contracting Roots of Human Rights' in: Journal of Peace Research, 45(3): 327-344.

Peksen, D. (2009) 'Better or Worse? The Effect of Economic Sanctions on Human Rights' in: Journal of Peace Research, 46(1): 59-77.

Poe, S.C. and Tate, C.N. (1994) 'Repression of human rights to personal integrity in the 1980s: a global analysis' in: American Political Science Review, 88(4): 853-872.

Richards, D.L., Gelleny, R.D. and Sacko, D.H. (2001) 'Money with a mean streak? Foreign economic penetration and government respect for human rights in developing countries', in: International Studies Quarterly, 45: 219-239. 
Richards, D.L. and Gelleny, R.D. (2001) 'Women’s Status and Economic Globalization’ in: International Studies Quarterly, 51: 855-876.

Rodrik, D., Subramanian, A. and Trebbi, F. (2004) 'Institutions Rule: The Primacy of Institutions over Geography and Integration in Economic Development' in: Journal of Economic Growth, 9: 131-165.

Sachs, J.D. (2001) 'Tropical Underdevelopment', National Bureau of Economic Research Working Paper No. w8119.

Shelton, D. (1999) 'The Promise of Regional Human Rights Systems' in: Weston, B.H. and Marks, S.P. (eds), The Future of International Human Rights, Ardsley, NY: Transnational Publishers, pp. 351-398.

Wood, R.M. and Gibney, M. (2010) 'The Political Terror Scale (PTS): a re-introduction and a comparison to CIRI' in: Human Rights Quarterly, 32(2): 367-400 


\section{Appendix}

Figure A1. Residual plot for the benchmark model (Table 2, column 4)

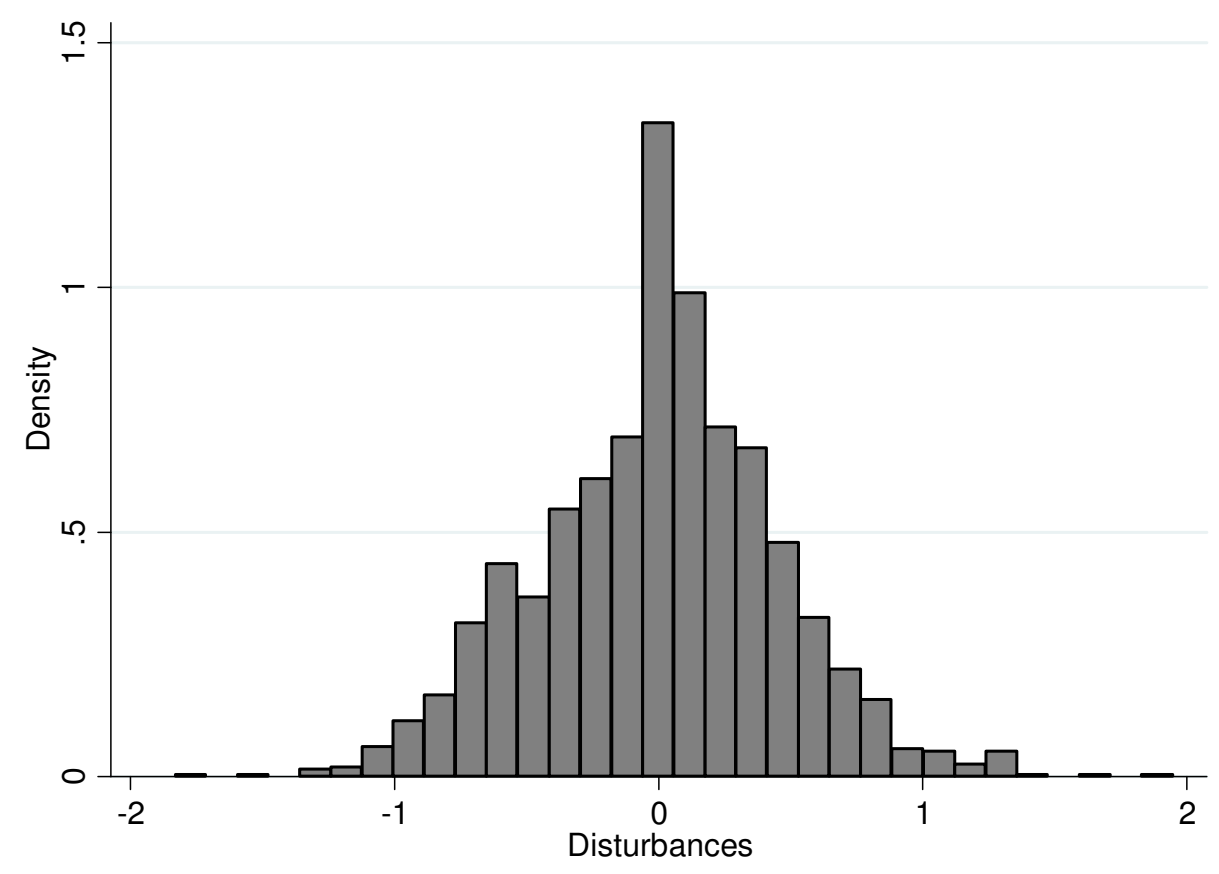


Figure 1(a) Scores US State Department Human Rights index, 1999

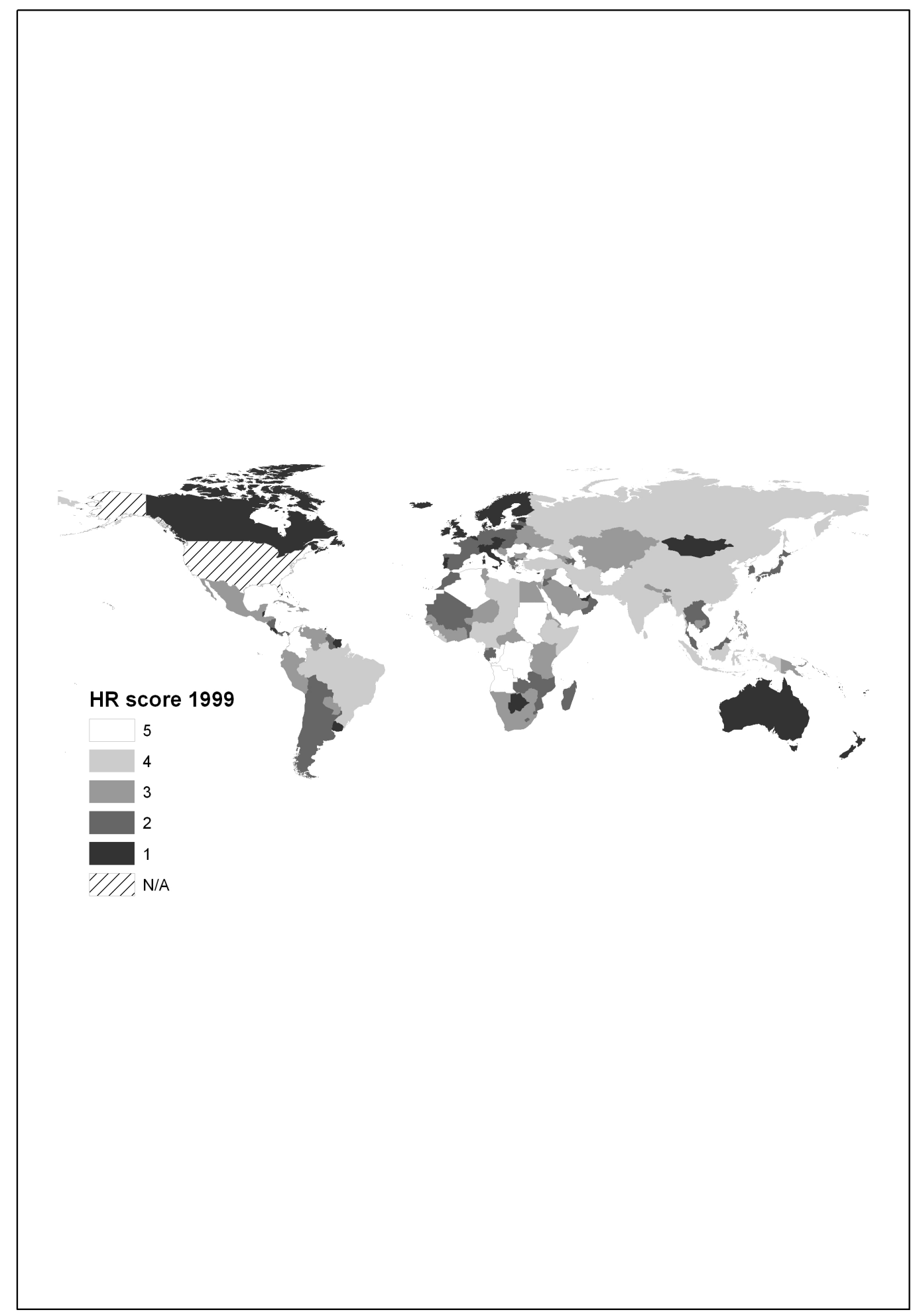


Figure 1(b) Changes in scores on US State Department Human Rights index, 1999 - 2009

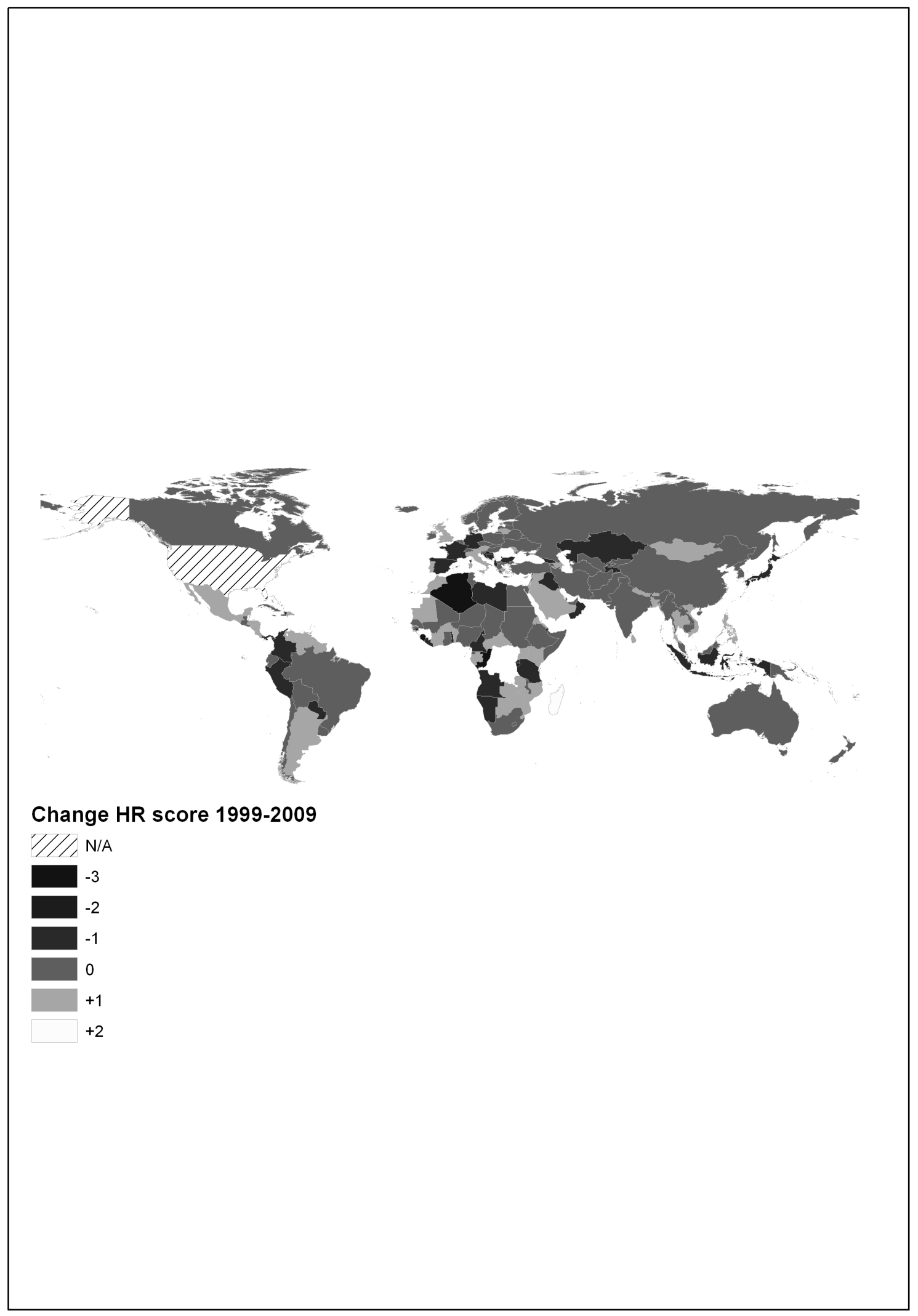


Table 1. Descriptive statistics

\begin{tabular}{lccc}
\hline Variable & Mean & Std. Dev. & $\begin{array}{l}\text { Moran's } \\
\text { I }\end{array}$ \\
\hline & & & \\
PTS score & 2,52 & 1,08 & $0.054 * * *$ \\
GDP (bln. constant 2000 dollars) & 147,44 & 484,44 & $0.066 * * *$ \\
Population (mln.) & 38,86 & 140,7 & $0.029 * * *$ \\
Urbanization & 54,42 & 22,64 & $0.061 * * *$ \\
Inflation & 24,87 & 609,38 & $0.003 * * *$ \\
Food production index & 109,02 & 16,95 & $0.010 * *$ \\
Resource value (bln.) & 630,18 & 1647,87 & $0.038 * * *$ \\
Life expectancy & 67,08 & 10,59 & $0.043 * * *$ \\
Violent conflict & 0,134783 & 0,341597 & $0.052 * * *$ \\
\hline Observations: $1610 . * * * \mathrm{p}<0.01, * * \mathrm{p}<0.05$. & &
\end{tabular}

Table 2. Effects on PTS scores

\begin{tabular}{|c|c|c|c|c|c|c|c|}
\hline & \multirow[b]{2}{*}{ pooled } & \multirow[t]{2}{*}{2} & \multirow[b]{2}{*}{ pooled } & \multirow[b]{2}{*}{ FE } & \multirow{2}{*}{$\begin{array}{l}5 \\
\text { LPM } \\
\text { pooled }\end{array}$} & \multirow{2}{*}{$\begin{array}{c}6 \\
\text { LPM } \\
\text { FE }\end{array}$} & \multirow{2}{*}{$\begin{array}{c}7 \\
\text { exog } \\
\text { FE }\end{array}$} \\
\hline & & & & & & & \\
\hline $\mathrm{GDP}^{\mathrm{a}}$ & $\begin{array}{c}-0.09 * * \\
(0.05)\end{array}$ & $\begin{array}{l}-0.19 \\
(0.25)\end{array}$ & $\begin{array}{c}-0.09 * * \\
(0.04)\end{array}$ & $\begin{array}{l}-0.18 \\
(0.25)\end{array}$ & $\begin{array}{c}-0.08 * * * \\
(0.02)\end{array}$ & $\begin{array}{l}-0.01 \\
(0.15)\end{array}$ & \\
\hline Population $^{\mathrm{a}}$ & $\begin{array}{c}0.94 * * * \\
(0.16)\end{array}$ & $\begin{array}{l}-0.24 \\
(2.87)\end{array}$ & $\begin{array}{c}0.93 * * * \\
(0.16)\end{array}$ & $\begin{array}{l}-0.02 \\
(2.83)\end{array}$ & $\begin{array}{c}0.36 * * * \\
(0.08)\end{array}$ & $\begin{array}{l}-0.27 \\
(1.72)\end{array}$ & $\begin{array}{c}0.11 \\
(2.56)\end{array}$ \\
\hline Urbanization & $\begin{array}{c}-0.01 * * * \\
(0.00)\end{array}$ & $\begin{array}{c}0.01 \\
(0.01)\end{array}$ & $\begin{array}{c}-0.01 * * * \\
(0.00)\end{array}$ & $\begin{array}{c}0.01 \\
(0.01)\end{array}$ & $\begin{array}{c}-0.00 * * * \\
(0.00)\end{array}$ & $\begin{array}{c}0.00 \\
(0.01)\end{array}$ & $\begin{array}{c}0.00 \\
(0.01)\end{array}$ \\
\hline Inflation $^{\mathrm{a}}$ & $\begin{array}{l}0.05 * \\
(0.03)\end{array}$ & $\begin{array}{c}0.02 \\
(0.02)\end{array}$ & $\begin{array}{c}0.05 \\
(0.03)\end{array}$ & $\begin{array}{c}0.02 \\
(0.02)\end{array}$ & $\begin{array}{c}0.01 \\
(0.02)\end{array}$ & $\begin{array}{l}-0.00 \\
(0.01)\end{array}$ & \\
\hline Food Production ${ }^{\mathrm{a}}$ & $\begin{array}{c}6.75 * * * \\
(1.16)\end{array}$ & $\begin{array}{c}0.59 \\
(1.16)\end{array}$ & $\begin{array}{c}6.79 * * * \\
(1.15)\end{array}$ & $\begin{array}{c}0.75 \\
(1.16)\end{array}$ & $\begin{array}{c}4.13 * * * \\
(0.61)\end{array}$ & $\begin{array}{l}1.15^{*} \\
(0.69)\end{array}$ & $\begin{array}{c}1.75 \\
(1.18)\end{array}$ \\
\hline Resources $^{a}$ & $\begin{array}{c}0.10 * * * \\
(0.01)\end{array}$ & $\begin{array}{l}-0.01 \\
(0.02)\end{array}$ & $\begin{array}{c}0.10 * * * \\
(0.01)\end{array}$ & $\begin{array}{l}-0.02 \\
(0.02)\end{array}$ & $\begin{array}{c}0.06 * * * \\
(0.01)\end{array}$ & $\begin{array}{c}-0.01 \\
(0.01)\end{array}$ & $\begin{array}{c}-0.02 \\
(0.02)\end{array}$ \\
\hline Life Expectancy & $\begin{array}{c}-0.03 * * * \\
(0.00)\end{array}$ & $\begin{array}{c}0.03 * * \\
(0.01)\end{array}$ & $\begin{array}{c}-0.03 * * * \\
(0.00)\end{array}$ & $\begin{array}{c}0.03 * * \\
(0.01)\end{array}$ & $\begin{array}{c}-0.01 * * * \\
(0.00)\end{array}$ & $\begin{array}{c}0.01 \\
(0.01)\end{array}$ & $\begin{array}{c}0.02 \\
(0.01)\end{array}$ \\
\hline Conflict & $\begin{array}{c}1.26 * * * \\
(0.06)\end{array}$ & $\begin{array}{c}0.57 * * * \\
(0.06)\end{array}$ & $\begin{array}{c}1.23 * * * \\
(0.06)\end{array}$ & $\begin{array}{c}0.57 * * * \\
(0.06)\end{array}$ & $\begin{array}{c}0.30 * * * \\
(0.03)\end{array}$ & $\begin{array}{c}0.08 * * \\
(0.04)\end{array}$ & \\
\hline Lag & & & $\begin{array}{c}0.29 * * * \\
(0.06)\end{array}$ & $\begin{array}{c}0.25 \\
(0.23)\end{array}$ & $\begin{array}{c}0.40 * * * \\
(0.06)\end{array}$ & $\begin{array}{c}0.01 \\
(0.23)\end{array}$ & $\begin{array}{c}0.28 \\
(0.24)\end{array}$ \\
\hline AR Error & & & & $\begin{array}{l}-0.35 \\
(0.27)\end{array}$ & & $\begin{array}{l}-0.10 \\
(0.24)\end{array}$ & $\begin{array}{l}-0.37 \\
(0.28)\end{array}$ \\
\hline Constant & $\begin{array}{c}3.88 * * * \\
(0.19)\end{array}$ & & $\begin{array}{c}3.14 * * * \\
(0.24)\end{array}$ & & $\begin{array}{c}0.72 * * * \\
(0.11)\end{array}$ & & \\
\hline Observations & 1,610 & 1,610 & 1,610 & 1,610 & 1,610 & 1,610 & 1,610 \\
\hline
\end{tabular}

Standard errors in

parentheses

$* * * \mathrm{p}<0.01, * * \mathrm{p}<0.05$,

$* \mathrm{p}<0.1$ 
Table 3. Regressions by

subsample

\begin{tabular}{|c|c|c|c|c|}
\hline & $\begin{array}{c}1 \\
\text { Latin } \\
\text { America }\end{array}$ & $\begin{array}{c}2 \\
\text { Europe }\end{array}$ & $\begin{array}{c}3 \\
\text { Africa } \\
\end{array}$ & $\begin{array}{c}4 \\
\text { Asia } \\
\end{array}$ \\
\hline $\mathrm{GDP}^{\mathrm{a}}$ & $\begin{array}{c}1.06 \\
(2.78)\end{array}$ & $\begin{array}{c}4.07 * * \\
(1.88)\end{array}$ & $\begin{array}{c}4.72 \\
(5.80)\end{array}$ & $\begin{array}{l}-0.25 \\
(0.39)\end{array}$ \\
\hline Population $^{\mathrm{a}}$ & $\begin{array}{c}-5.82 \\
(35.43)\end{array}$ & $\begin{array}{c}15.49 \\
(37.42)\end{array}$ & $\begin{array}{c}-3.97 \\
(14.61)\end{array}$ & $\begin{array}{l}-0.74 \\
(3.62)\end{array}$ \\
\hline Urbanization & $\begin{array}{c}0.03 \\
(0.03)\end{array}$ & $\begin{array}{c}-0.07 * * \\
(0.03)\end{array}$ & $\begin{array}{c}0.02 \\
(0.02)\end{array}$ & $\begin{array}{l}-0.02 \\
(0.03)\end{array}$ \\
\hline Inflation $^{\mathrm{a}}$ & $\begin{array}{l}-0.90 \\
(2.99)\end{array}$ & $\begin{array}{c}0.76 \\
(1.40)\end{array}$ & $\begin{array}{c}0.02 \\
(0.02)\end{array}$ & $\begin{array}{l}-0.28 \\
(3.92)\end{array}$ \\
\hline Food Production ${ }^{\mathrm{a}}$ & $\begin{array}{l}-1.81 \\
(3.52)\end{array}$ & $\begin{array}{l}4.64 * * \\
(2.27)\end{array}$ & $\begin{array}{c}0.35 \\
(2.10)\end{array}$ & $\begin{array}{c}1.25 \\
(3.26)\end{array}$ \\
\hline Resources $^{\mathrm{a}}$ & $\begin{array}{l}-0.02 \\
(0.07)\end{array}$ & $\begin{array}{l}-0.09 \\
(0.06)\end{array}$ & $\begin{array}{l}-0.04 \\
(0.05)\end{array}$ & $\begin{array}{c}0.01 \\
(0.09)\end{array}$ \\
\hline Life Expectancy & $\begin{array}{c}0.04 \\
(0.05)\end{array}$ & $\begin{array}{l}-0.05 \\
(0.04)\end{array}$ & $\begin{array}{c}0.01 \\
(0.02)\end{array}$ & $\begin{array}{l}0.08 * * \\
(0.04)\end{array}$ \\
\hline Conflict & $\begin{array}{l}-0.10 \\
(0.25)\end{array}$ & $\begin{array}{c}0.84 * * * \\
(0.22)\end{array}$ & $\begin{array}{c}0.57 * * * \\
(0.09)\end{array}$ & $\begin{array}{c}0.79 * * * \\
(0.15)\end{array}$ \\
\hline Lag & $\begin{array}{l}-0.05 \\
(0.30)\end{array}$ & $\begin{array}{l}-0.08 \\
(0.29)\end{array}$ & $\begin{array}{c}0.11 \\
(0.25)\end{array}$ & $\begin{array}{l}-0.01 \\
(0.27)\end{array}$ \\
\hline AR Error & $\begin{array}{l}-0.09 \\
(0.32) \\
\end{array}$ & $\begin{array}{c}0.09 \\
(0.29)\end{array}$ & $\begin{array}{c}-0.04 \\
(0.28)\end{array}$ & $\begin{array}{l}-0.04 \\
(0.28)\end{array}$ \\
\hline $\begin{array}{l}\text { Observations } \\
\text { Standard errors in parentheses } \\
* * * \mathrm{p}<0.01, * * \mathrm{p}<0.05, * \mathrm{p}<0.1 \\
{ }^{\mathrm{a}} \text { For readability, coefficient is } \mathrm{m} \\
1000 .\end{array}$ & by & 255 & 582 & 231 \\
\hline
\end{tabular}


Figure 2. Spatial lag effects by decay parameter.

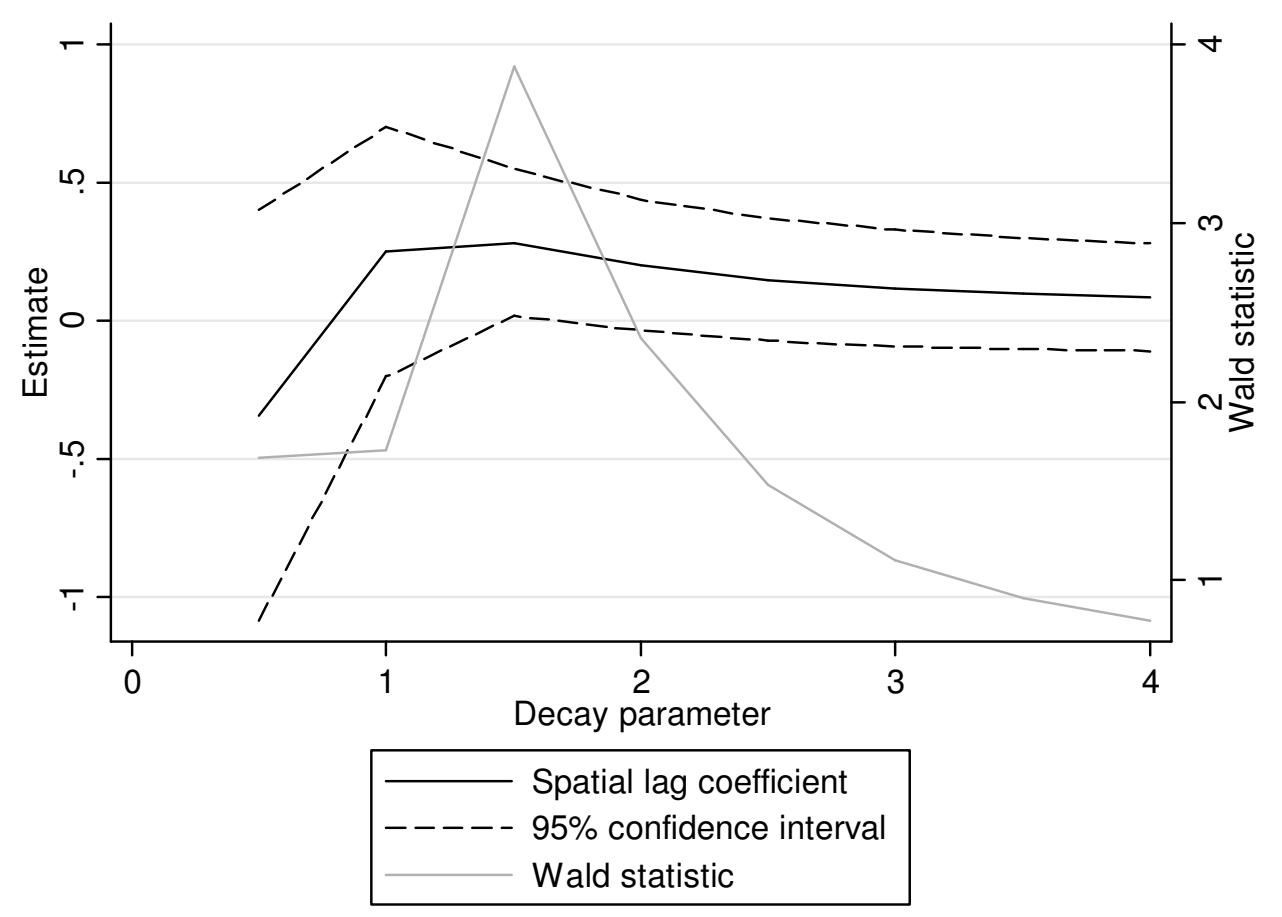

